\title{
As modernidades nas Américas: desde as vanguardas até hoje
}

Fiona McMahon e Paul-Henri Giraud

Tradutor. Lucilia Wuillaume

\section{(2) OpenEdition}

Journals

\section{Edição electrónica}

URL: https://journals.openedition.org/ideas/3151

DOI: 10.4000/ideas.3151

ISSN: 1950-5701

\section{Este artigo é uma tradução de:}

Modernités dans les Amériques : des avant-gardes à aujourd'hui - URL : https://

journals.openedition.org/ideas/2544 [fr]

Outra(s) tradução(ões) deste artigo:

Modernities in the Americas: from the avant-gardes to nowadays - URL : https://

journals.openedition.org/ideas/3125 [en]

Modernidades en las Américas: de las vanguardias a la actualidad - URL : https://

journals.openedition.org/ideas/3131 [es]

\section{Editora}

Institut des Amériques

\section{Refêrencia eletrónica}

Fiona McMahon e Paul-Henri Giraud, «As modernidades nas Américas: desde as vanguardas até hoje», IdeAs [Online], 11 | 2018, posto online no dia 21 junho 2018, consultado o 18 outubro 2022. URL: http://journals.openedition.org/ideas/3151 ; DOI: https://doi.org/10.4000/ideas.3151

Este documento foi criado de forma automática no dia 18 outubro 2022.

\section{c) (i) $९$}

Creative Commons - Atribuição-NãoComercial-SemDerivações 4.0 Internacional - CC BY-NC-ND 4.0 https://creativecommons.org/licenses/by-nc-nd/4.0/ 


\title{
As modernidades nas Américas: desde as vanguardas até hoje
}

\author{
Fiona McMahon e Paul-Henri Giraud
}

Tradução : Lucilia Wuillaume

1 Atualmente, repensar a questão da modernidade - literária, artística, social ou política - significa empregar a palavra no plural. Essa escolha implica em não nos limitarmos ao termo plurívoco, e, muitas vezes ambíguo, de modernismo. Esse último, frequentemente convocado para designar o imaginário cultural da modernidade, tem dificuldade em dar conta das diferenças que se manifestam na forma de pensar a relação com o tempo, a história e a cultura. "A modernidade não é um movimento, como o Dada ou o Imagismo. Quando a história literária decide designar como modernismo um certo movimento, inglês ou espanhol, o termo toma, imediatamente, um sentido técnico. Ele se fixa. Somente participa da modernidade de forma fragmentar." (Meschonnic H., 1988:26).

O conceito de modernidade, na esteira de suas variações europeias reveladas às vésperas do século vinte - tecnológicas, políticas, artísticas -, está, da mesma forma, marcado pela disparidade das experiências nos locais e nos espaços das Américas. O presente número da revista IdeAs procura colocar em perspectiva esse conceito no universo das artes e da literatura, a partir do momento-chave das vanguardas nascidas da Primeira Guerra Mundial. Quais são, nas Américas, os ecos das profundas transformações culturais introduzidas na Europa e, ao contrário, quais formas de resistência vêm iluminar as produções americanas?

3 Trata-se, assim, de olhar, a partir de uma perspectiva completamente nova, um fenômeno multiforme e multilíngue com o objetivo de identificar linhas de força ou de compartilhamento. Para os diferentes espaços culturais das Américas, que horizontes são oferecidos pelo paradigma, simultaneamente destrutor e criador da modernidade? "Em nome da radicalidade artística e do conceito de ruptura", deixamos de lado ou subestimamos diversas expressões individuais ou coletivas consideradas híbridas, locais, tardias ou antimodernas" pode-se ler em relação à arte (Grenier C., 2013:16). 
4 Da mesma forma, na literatura, é com o modelo do eterno futuro do passado que continuamos a nos comparar: "é preciso ser antigo para ter qualquer chance de ser moderno ou de decretar a modernidade" (Casanova P., 2008: 137). Daí a busca sistemática pelos antepassados do moderno chegando até aos mundos ditos "primitivos" ou indígenas. Para retomar e inverter a antítese clássica utilizada pelo argentino José Domingo Sarmiento (2006) em pleno século XIX, muitas vezes a barbárie parece mais moderna do que a "civilização", desde que saibamos nos resguardar da tentação folclorista - o que fazem as estilizações do moderno quando se aplicam ao material vernacular.

5 As evidentes diferenças, assim como os pontos de convergência, entre as Américas anglófonas e hispanófonas - lamentando que não tenha sido possível representar os universos lusófono e francófono nesse número - deveriam permitir uma melhor compreensão das especificidades de cada uma dessas regiões, e seus próprios contrates internos, das primeiras décadas do século XX até o período atual. Pois, é apenas hoje que as modernidades sucessivas encontraram, simultaneamente, sua forma exata e sua resposta, tanto nos questionamentos dos pensamentos pós-coloniais ou descoloniais, quanto em alguns prolongamentos das artes e da literatura, e até mesmo da etnologia.

\section{Pintura, fotografia e dança}

6 A vanguarda do início do século XX, marcada por uma sucessão de "-ismos", desenvolveu ativamente a utopia de misturar as artes e fazer com que convirjam. No México, na ebulição cultural que sucedeu à Revolução, literatura, pintura, gravura, fotografia e caligramas se encontram na revista Irradiador (1923), que, em seu subtítulo, define-se como "Revista de Vanguarda", projetor internacional de estética nova". O culto ao novo, a rejeição agressiva ao antigo, a valorização estética do arbitrário e do fragmentar, a poesia caótica da cidade moderna, segundo Isabelle Pouzet, definem a essência do efêmero movimento "Estridentista," do qual a revista foi porta-voz.

7 Na capa do terceiro número, uma fotografia de Edward Weston feita em 1992 em Ohio, intitulada Steel, apresenta uma linha de chaminés de fábrica em contre-plongée. Essa introdução explosiva de uma imagem bruta e estilizada da indústria norte-americana na primeira página do Irradiador marca o aparecimento, no México, da Straight Photography e manifesta uma intensa aspiração à modernidade da parte dos artistas desse país, sob a impulsão de seu grande vizinho do norte. Dessa forma, a estadia de Weston no México, entre 1923 et 1926, representa o traço de união entre os vanguardistas ao norte e ao sul do Río Grande.

8 Com a institucionalização da Revolução mexicana, à euforia iconoclasta do Irradiador, cujo entusiasmo militante e ecumênico poderia quase ser qualificado de ingênuo, seguiu-se uma utilização mais crítica do meio fotográfico. Contra a "mitologia de um modernismo triunfante", em descompasso com a "mise en scène nacionalista na cultura visual" que a pintura muralista ou a escultura celebrando a glória do regime implementaram durante os anos 1920-1930, Erica Segre discerne na fotografia mexicana contemporânea, e principalmente, em Augustín Jiménes, uma "corrente reflexiva atormentada pelo enquadramento e o poder coercitivo profundo". 
9 Ela se concentra na valorização das "estéticas dissidentes" que, por seu jogo de sombras e grades, sugerem a reclusão dos mexicanos em um unanimismo nacional. Inicialmente subterrânea, essa surda "indisciplina" fotográfica só se torna evidente nos anos 1950-1960 nas fotos de Nacho López, Rodrigo Moya ou Héctor García. Os retratos, realizados por esse último, do pintor David Alfaro Siqueiros (1896-1974) atrás das grades da prisão de Lecumberri no final dos anos 60, fazem desse artista marxista um verdadeiro ícone. Permanecer moderno, para Siqueiros, implica em poder circular entre os status antinômicos de pintor vanguardista, pintor oficial e pária, mediante a performance interrompida de seus feitos artístico-políticos. O muralista, que jamais cessou de rejeitar a pintura em cavalete, conseguiu, apesar de tudo, sempre permanecer no "campo" midiático, e isso graças ao enquadramento fotográfico.

10 Seu contemporâneo americano, Stuart Davis (1892-1964), é um caso bastante diferente. Kamila Benayada vê em seu trabalho uma "redefinição do modernismo" "através da série dos Champion, pintada durante a Guerra Fria". Ainda que a construção da obra de arte esteja focada na relação que mantém com o mundo, a prática de Davis consiste em tornar mais complexos os termos dessa relação criando um diálogo com suas próprias obras anteriores, assim como com as de seus predecessores modernistas, ampliando a esfera artística até incluir o ambiente visual da cultura popular.

11 A transitividade da obra pintada vincula os gestos picturais ao mundo e a seus contextos semióticos. Evidenciada na superfície da tela, a relação do artista com seu tempo subentende um dispositivo de invenção pictural que, desprezando as fronteiras genéricas, celebra o movimento e a troca.

Quanto a Elsa Crousier, esta narra a trajetória evolutiva da crítica de arte de origem uruguaia Marta Traba, que criou o Museu de Arte Moderna de Bogotá em 1963. Após ter sustentado um discurso internacionalista e cosmopolita sobre a arte, Traba se empenhou, a partir dos anos 60, em definir a arte latino-americana contra o Norte - a Europa, mas ainda mais os Estados Unidos. A "resistência" latino-americana passava, segundo ela, pela rejeição dos estereótipos superficialmente modernos da Arte Pop e pelo mergulho na identidade regional e na psiché ameríndia. Para serem modernos, os artistas latino-americanos deveriam, então, de uma certa forma, tornar-se antimodernos.

13 Da mesma forma, pode-se observar, com Claudie Servian, que a modernidade e o descentramento cultural por ela produzido, levam a uma metamorfose da paisagem coreográfica dos Estados Unidos durante as primeiras décadas do século vinte. Nos escritos teóricos das coreógrafas Martha Graham (1894-1991) e Doris Humphrey (1895-1958) aqui analisados, a busca pela modernidade implica em uma atualização do mais antigo passado. A fantasia da origem, acompanhada de uma rejeição do modernismo tecnológico, conduz a dança a explorar arcaísmos perdidos, enterrados no inconsciente ou identificados com os modelos que foram tomados emprestados das culturas ameríndias.

O retorno às artes tribais e ao psiquismo primitivo opõe o mecanismo da modernidade aos movimentos do corpo, no que esses têm de intuitivo ou natural. A modernidade do corpo estaria, então, relacionada com seu potencial expressivo e significante, em uma relação de contato ou de comunhão com seu ambiente. A inteiração com o solo garantiria a autenticidade da criação, ao mesmo tempo em que faria surgir cenários da história americana, como em algumas coreografias dos anos 30. Assim, a ruptura com a tradição acadêmica europeia passa pelo mito de uma volta às origens. 

de neobarroco, estudada aqui por Marcos Rico Domínguez. A arte colonial hispanoamericana faz a síntese das civilizações pré-hispânicas e do catolicismo espanhol. Nos anos 60, a categoria estética barroco, inventada no final do século XIX, e teorizada, principalmente, na primeira metade do século XX, foi reivindicada por uma constelação de autores cubanos e analisada pelo mexicano Octavio Paz (1914-1998) como um dos fundamentos da modernidade latino-americana. Paz faria, assim, a junção entre a época histórica dita "moderna" (séculos XVI - XVIII), apogeu do Império Hispânico, rico em novas sementes, e a desconcertante proliferação dos sinais de vanguarda dos anos 60 , valorizando o substrato indígena de uma arte aparentemente muito ocidental e "moderna".

\section{Romance e poesia}

Enquanto as modernidades americanas, em sua dimensão estética, remetem tradicionalmente à experimentação formal dos artistas e autores das primeiras décadas do século XX e à sua relação com a vanguarda europeia, Céline Mansanti nos convida a deixar de lado os discursos contestatários para refletir sobre a relação entre o modernismo literário anglo-americano e a literatura dita mainstream do período entreguerras, atualmente, objeto de reavaliações críticas. Em seu artigo intitulado " $\mathrm{Au}$ delà des clichés et de la satire: le débat sur l'expatriation et le modernisme dans un roman "mainstream" : The French They are a Funny Race, de Lyon Mearson (1931)", Céline Mansanti coloca a questão do contexto de produção de uma obra pouco estudada para elucidar convergências de influência entre, por um lado, o teatro modernista no qual se desenvolve a vida dos expatriados em Paris, campo de experiência reflexivo que problematiza as convenções discursivas da literatura, e, por outro lado, a cultura "middlebrow" ou "média", na qual a transparência dos universos ficcional e estilístico participa das regras da sociedade de consumo emergente.

Em "Bill \& Carlos: Les Amériques de William Carlos Williams", Anna Aublet lança uma nova luz sobre a especificidade sociocultural da obra do poeta William Carlos Williams (1983-1963) e sobre a dupla identidade linguística e cultural do autor americano, filho de uma porto-riquenha. Partindo do polêmico esquema da modernidade poética, reflete-se sobre a reconquista da história e dos mitos do continente americano pela poesia, reconquista essa que, para Williams, repousa sobre as operações paradoxais de desconstrução e construção. Anna Aublet estuda o reexame dos mitos fundadores da história americana realizado por Williams em suas obras romanescas dos anos vinte, The Great American Novel (1923) et In the American Grain (1925).

Os retornos do autor a suas raízes hispanofônicas fazem parte de uma busca identitária individual e coletiva que atravessa todo o continente, de norte a sul. o deciframento dos códigos semânticos próprios a Williams está associado à hipótese de uma língua vernacular, democrática, mas disparate, oriunda da miscigenação. Os horizontes da novidade, objeto, nesse poeta, de uma busca obsedante, abrem-se, assim, à língua espanhola, legado materno e vestígio do passado colonial das Antilhas.

19 A relação com o passado e com as origens das letras norte-americanas também está no cerne do artigo de Aurore Clavier, "New contours suggested by old words" : la modernité américaine au tamis de l'archéologie poétique". A obra dos anos 1920 dos poetas Wallace Stevens, Marianne Moore e William Carlos Williams, foi aqui conectada a uma dupla 
temporalidade, retrospectiva e prospectiva, simultaneamente. A reflexão de Aurore Clavier baseia-se nas modalidades arqueológicas da invenção modernista como paradigma de escritura para vincular as explorações e escavações do passado à emergência de um idioma poético sensível à dialética entre superfície e profundidade, entre contingências do presente e narrativa original. Se o empreendimento historiográfico da modernidade consiste em redefinir os modos de escritura do passado norte-americano, também a identidade cultural nacional (de acordo com Aurore Clavier) faz referência à fascinação exercida sobre esses poetas pelo tempo longo.

Dessa forma, a relação do continente americano com a modernidade deve ser lida pelo espelho da atividade mito-poética de seus escritores. $O$ deslocamento que se opera em relação aos pontos de ancoragem é tanto de ordem estética, quanto política e geográfica, de norte a sul e de leste a oeste. Em sua abordagem hemisférica, Aurore Clavier tenta abraçar a pluralidade implicada no empreendimento de reescritura da origem, ou seja, a busca de um presente enraizado em locais plurais. Principalmente para Williams, o contexto histórico e social de In the American Grain engloba a América Central, o Caribe e as nações ameríndias. Ele permite enfatizar a hipótese de um modernismo americano que já não pode ser pensado como culturalmente ou politicamente neutro.

21 Como bem lembra François Hugonnier em seu artigo "Repenser les modernismes à la lueur de l'œuvre de Jerome Rothenberg", a vanguarda europeia havia deslocado o destaque para as margens da prática artística; com isso, abria para a modernidade americana o caminho para a heterogeneidade das formas e das culturas. A pluralidade revela-se como um dos principais impulsores do modernismo, proteiforme e internacional. Ler Rothenberg (nascido em 1931), é descobrir a defesa de um novo teatro de modernismos, que leva em consideração, para além do solo americano, uma miríade de fontes locais e "globais" de diferentes épocas. François Hugonnier enfatiza o papel de Rothenberg como cartógrafo de uma poética engajada, pan-americana e cosmopolita, poliglota e iconoclasta. Assim, o militantismo editorial de Rothenberg realizou o projeto inédito de fazer com que a modernidade literária pudesse ser lida à luz dos textos autóctones, frequentemente traduzidos.

22 Esse artigo ressalta a pertinência do gesto antológico, compilador de poesias subrepresentadas ou encobertas pela chapa monolítica do cânone ocidental, no quinquagésimo aniversário desse volume pioneiro que foi o Technicians of the Sacred: A Range of Poetries from Africa, America, Asia, Europe \& Oceania (1968).

Ao fim desse percurso e acompanhando William Mohr, podemos nos perguntar como as mutações pós-modernas influenciaram a formação das comunidades heterogêneas no continente americano, investidas como leitores, autores, editores, gráficas, ou críticos, na vida das letras, na época contemporânea. Preocupado em explorar as condições sociopolíticas da produção literária e tendo como pano de fundo a trajetória de sua própria obra poética, no artigo intitulado "La côte Ouest comme capitale littéraire dans la république de la littérature: les éditeurs indépendants comme agents plastiques de l'hypermodernité", William Mohr parte do modelo teórico dito "circuito de comunicação" proposto pelo historiador americano Robert Darnton, especialista em História do Livro - para se interessar pela construção de um cânone poético da Costa Oeste, nos anos 1955-1985, graças à sinergia editorial de um grupo de poetas e editores independentes. Os esforços coletivos desses autores culturais fazem-nos contemplar uma nova narrativa da (pós)modernidade à luz da disseminação cultural. Abrir as linhas de 
demarcação de um cânone poético, como faz a comunidade literária, celebrada, aqui, por William Mohr, representa participar dos deslizamentos de pensamento e discurso que, até hoje e de diferentes formas, dão primazia à mudança.

\section{Fora do Ocidente?}

A emergência da modernidade não pode ser pensada sem refletirmos sobre as articulações entre o universo artístico e o âmbito sociopolítico. Citando, mais uma vez, Meschonnic, sabemos que as fronteiras políticas e territoriais do moderno foram definidas pelo Ocidente: "A modernidade. Inútil acrescentar: ocidental. A modernidade é europeia. E se chamarmos de ocidente a Europa, e a América do Norte, ela é ocidental" (1988: 27). Mas a modernidade coloca-se também como "terreno de um trabalho do sentido" (1988: 26), sujeito à temporalidade e ao espaço nos quais todas as sociedades e as culturas evoluem atualmente.

Tendo entrado nesse campo, os aprofundamentos da crítica pós-colonial contribuíram para evidenciar a codificação ocidental - europeia e americana - que constitui uma grade de leitura homogênea e universal. Mediante formas de resistência opostas à uniformização dos modelos de saber, esboça-se hoje em dia um conceito de "modernidade" em sua pluralidade, que devemos cruzar com uma perspectiva extraocidental.

Assim, Smaro Kamboureli questiona a inscrição da modernidade nas culturas subestimadas pelo ocidente apresentando o exemplo da representação da cultura Inuit de Igloulik, uma pequena comunidade do Tuvuna nos territórios do norte do Canadá. Seu artigo intitulado "L'Opéra dans l'Arctique : Knud Rasmussen, traversées de la modernité", revela um enfrentamento dialógico entre duas temporalidades.

28 Entre o depoimento do etnógrafo Knud Rasmussen sobre sua experiência entre os Iglulingmiurt - Du Grœnland au Pacifique: deux ans d'intimité avec des tribus d'Esquimaux inconnus (trad. do dinamarquês, 1929) - e a reapropriação dessa narrativa e desse momento histórico pelo filme de Norman Cohn, Le Journal de Knud Rasmussen (2006), percebemos a distância que separa o olhar do etnógrafo sobre seu empreendimento colonizador e uma leitura epistemológica da cultura inuit na época contemporânea.

29 A presença do ocidente nos territórios do norte do Canadá no início do século XX como a ópera entre os inuits - é o sinal, para Rasmussen, da modernidade "negativa", um conceito que traduz a seus olhos o travestimento da cultura inuit. A relação com esse tempo passado, marcado no discurso do etnógrafo pela dissonância entre modernidade e alteridade, evolui no filme de Cohn em direção a um novo olhar, que reconfigura o conceito de "autenticidade" autóctone, assinalando, ao mesmo tempo, os limites do regime colonial e os da modernidade, em relação à construção identitária. 0 enclausuramento na temporariedade se vê, assim, recusado e o filme convida a ler a cultura autóctone de forma diacrônica, descompartimentalizada, longe do mito da origem e do culto do "primitivo".

No encontro com o arquivo ocidental e os modos de produção dos inuits, forma-se uma imagem viva da experiência da alteridade. A narrativa histórica revisitada pelo cinema inuit abre-se ao desconhecido, mostrando a transformação exercida pelo artefato sobre a experiência do Outro. 

(2015: 28), um modelo sujeito às operações das redes nas quais se confundem alteridades e alterações radicais, qualquer que seja a temporalidade. $\mathrm{Na}$ crítica americana, ao conceito de modernidade veio se juntar o paradigma transnacional para definir as redes de produção cultural e, assim, desenhar uma nova cartografia do moderno. A ênfase colocada em uma teoria diaspórica da literatura pelo "Institut TransCanada" e por sua diretora Smaro Kamboureli trilha esse caminho (Scandalous Bodies, 2000).

Da mesma forma, para Jahan Ramazani (2009), o debate em torno da emergência de uma "poética transnacional" revela a amplitude das influências devido à porosidade das fronteiras culturais, a partir das vanguardas e para além delas. Deslocando o centro em direção à periferia, essa nova leitura teórica, baseada em um modelo da influência dita de entrelaçamento ["enmeshment"], nos permite ouvir as ressonâncias da cultura póscolonial em nossa percepção atual dos desenvolvimentos sucessivos da modernidade, durante todo o século XX e até os dias de hoje.

\section{BIBLIOGRAFIA}

Casanova, Pascale, La République mondiale des lettres [1999], éd. rev. et corr., Paris, Seuil, « Points Essais », 2008.

Friedman, Susan, Planetary Modernisms: Provocations on Modernity across Time, New York, Columbia University Press, 2015.

Grenier, Catherine, « Le monde à l'envers? », in Modernités plurielles : 1905-1970, Paris, Centre Pompidou, 2013, p. 14-31.

Meschonnic, Henri, Modernité modernité, Paris, Gallimard/Verdier, « Folio Essais », 1988.

Kamboureli, Smaro. Scandalous Bodies: Diasporic Literature in English Canada. Toronto: Oxford UP, 2000.

Ramazani, Jahan, A Transnational Poetics, Chicago, University of Chicago Press, 2009.

Sarmiento, Domingo Faustino, Facundo: Civilización y barbarie [1845], Madrid, Cátedra, « Letras hispánicas », 2006.

\section{AUTORES}

\section{FIONA MCMAHON}

Fiona McMahon est maître de conférences en littérature américaine à l'Université de Bourgogne Franche-Comté. Ses recherches portent sur le modernisme, les poétiques des $\mathrm{XX}^{\mathrm{e}}$ et $\mathrm{XXI}^{\mathrm{e}}$ siècles (US/CAN), ainsi que sur des relations intermédiales dans les arts et les lettres. Parmi ses travaux sont parus deux monographies : Charles Reznikoff : une poétique du témoignage (L'Harmattan, 2011) et H.D. Trilogy (Atlande, 2013) ; elle a co-dirigé un ouvrage collectif à paraitre chez Classiques 
Garnier en 2018, Penser le genre en poésie contemporaine.

Fiona McMahon is Associate Professor of American Literature at the Université de Bourgogne Franche-Comté (Dijon, France). In addition to articles on Modernist and contemporary poetry (US/CAN), and on intermediality in the arts and literature, she is the author of Charles Reznikoff: une poétique du témoignage (L'Harmattan, 2010), H.D. Trilogy (Atlande, 2013) and has co-edited a book of essays, Penser le genre en poésie contemporaine(forthcoming in 2018 with Classiques Garnier).

\section{PAUL-HENRI GIRAUD}

Professeur en études hispaniques contemporaines à l'Université de Lille, il est directeur adjoint du Centre d'études en civilisations, langues et littératures étrangères (CECILLE) et Secrétaire général de l'Institut des Amériques. Il a publié Octavio Paz: Vers la transparence (2002, édition en espagnol revue et augmentée 2014) et Manuel Álvarez Bravo : L'Impalpable et l'imaginaire (2012). Ces dernières années, il a notamment co-dirigé l'ouvrage 1910: México entre dos épocas (El Colegio de México, 2014) ainsi que deux dossiers monographiques : Fotografía, cultura y sociedad en América latina. Nuevas perspectivas (2015) et Cosmopolitismes dans les Amériques, 1900-1960 (2018), numéros 219 et 223 de L'Ordinaire des Amériques (http://orda.revues.org). paul-henri.giraud@univ-lille3.fr 